\title{
Iron levels in the human brain: a post-mortem study of age-related changes and anatomical region differences
}

\author{
Patrícia Ramos ${ }^{\mathrm{a}}$, Agostinho Santos ${ }^{\mathrm{b}, \mathrm{c}, \mathrm{d}, \mathrm{e}}$, Nair Rosas Pinto ${ }^{\mathrm{b}}$, Ricardo Mendes ${ }^{\mathrm{b}}$, \\ Teresa Magalhães ${ }^{\mathrm{b}, \mathrm{c}, \mathrm{d}, \mathrm{f}}$, Agostinho Almeida ${ }^{\mathrm{a}, *}$ \\ ${ }^{a}$ REQUIMTE, Department of Chemical Sciences, Laboratory of Applied Chemistry, Faculty of Pharmacy, Porto \\ University, Rua de Jorge Viterbo Ferreira 228, 4050-313, Porto, Portugal. \\ ${ }^{b}$ National Institute of Legal Medicine and Forensic Sciences, North Branch, Jardim Carrilho Videira, 4050-167, Porto, \\ Portugal. \\ ${ }^{c}$ CENCIFOR - Forensic Science Center, Largo da Sé Nova, s/n, 3000-213, Coimbra, Portugal. \\ ${ }^{d}$ Faculty of Medicine, Porto University, Al. Prof. Hernâni Monteiro, 4200-319, Porto, Portugal. \\ ${ }^{e}$ School of Health Sciences, Minho University, Campus Gualtar, 4710-057, Braga, Portugal. \\ ${ }^{f}$ Biomedical Sciences Institute Abel Salazar, Porto University, Rua de Jorge Viterbo Ferreira 228, 4050-313, Porto, \\ Portugal.
}

* Corresponding author:

Department of Chemical Sciences

Laboratory of Applied Chemistry

Faculty of Pharmacy

Porto University

Rua de Jorge Viterbo Ferreira 228

4050-313, Porto

Portugal

Tel.: +351220428667

Fax: +351222003977

E-mail address: aalmeida@fff.up.pt 


\section{Abstract}

The link between brain iron homeostasis and neurodegenerative disease has been the subject of extensive research. There is increasing evidence of iron accumulation during ageing, and altered iron levels in some specific brain regions in neurodegenerative disease patients have been reported.

Using graphite furnace atomic absorption spectrometry after microwave-assisted acid digestion of the samples, iron levels were determined in 14 different areas of the human brain [frontal cortex, superior and middle temporal, caudate nucleus, putamen, globus pallidus, cingulated gyrus, hippocampus, inferior parietal lobule, visual cortex of the occipital lobe, midbrain, pons (locus coeruleus), medulla and cerebellum (dentate nucleus)] of $n=42$ adult individuals $(71 \pm 12$ years old, range: 53-101 years old) with no known history or evidence of neurodegenerative, neurological or psychiatric disorders.

It was found that the iron distribution in the adult human brain is quite heterogeneous. The highest levels were found in the putamen (mean $\pm \mathrm{sd}$, range: $855 \pm 295 \mu \mathrm{g} / \mathrm{g}, 304-1628 \mu \mathrm{g} / \mathrm{g}$ ) and globus pallidus $(739 \pm 390 \mu \mathrm{g} / \mathrm{g}, 225-1870 \mu \mathrm{g} / \mathrm{g})$, and the lowest levels were observed in the pons $(98 \pm 43$ $\mu \mathrm{g} / \mathrm{g}, 11-253 \mu \mathrm{g} / \mathrm{g})$ and medulla $(56 \pm 25 \mu \mathrm{g} / \mathrm{g}, 13-115 \mu \mathrm{g} / \mathrm{g})$.

Globally, iron levels proved to be age-related. The positive correlation between iron levels and age was most significant in the basal ganglia (caudate nucleus, putamen and globus pallidus).

Compared with the age-matched control group, altered iron levels were observed in specific brain areas of one Parkinson's disease patient (the basal ganglia) and two Alzheimer's disease patients (the hippocampus).

Keywords: human brain; iron levels; post-mortem analysis; ageing; neurodegenerative diseases 


\section{Introduction}

According to the US National Institute of Aging and WHO's 2011 "Global Health and Aging" report [1] and as a result of longer life expectancy, chronic and degenerative diseases will become the most prevalent diseases worldwide over the next several decades.

The aetiology of neurodegenerative diseases (NDs) is multifactorial, and it is assumed to involve a complex interaction between (natural) ageing, genetic predisposition and environmental factors [2]. Disturbances in trace element (TE) homeostasis in specific areas of the brain $[3,4]$ have been identified as contributing to the development of many NDs.

Iron $(\mathrm{Fe})$ is the most abundant transition metal in the human body and has many essential functions in the brain and nervous system, such as oxygen transport, mitochondrial respiration, protein and DNA synthesis, myelination, dendrite development and neurotransmitter biosynthesis $[5,6]$. Interestingly, it has been observed that patients with NDs such as Parkinson's and Alzheimer's disease tend to accumulate Fe in their nervous system [7-12], suggesting a role for this transition metal in these disorders. Fe accumulation leads to excessive production of reactive oxygen species, protein, DNA and phospholipid oxidation and, ultimately, to structural and functional damage [3].

Despite the intensive research that has been conducted on the relationship between TE and ND, the evidence is still fragmentary, and the exact role of TE remains poorly understood. Its direct determination in human brain samples from both healthy individuals and patients with ND is crucial for a better understanding of the underlying disease mechanisms and the development of chelation therapies, but most of the current information about the relationship between TE and human brain functioning is based on animal studies $[13,14]$ or relies on determinations in cerebrospinal fluid, 
blood or serum samples $[13,15-19]$. Studies on TE levels in normal and pathological human brains are scarce, limited to a few brain areas [20-23] and/or involve a small number of subjects [24, 25].

Based on this background, the main goal of the present study was to directly quantify Fe levels in normal human brain tissue, extending the number of brain areas and the number of subjects studied, to evaluate a) the regional anatomic differences and b) age-related changes in Fe levels within the brain tissue. This type of information is indispensable for interpreting the data obtained from ND patients.

\section{Materials and methods}

\section{Subjects}

Brain samples were collected from men $(n=27 ; 67 \pm 11$ years old $)$ and women $(n=15 ; 77 \pm 12$ years old) not registered in the Portuguese National Registry of Refusal to Organ Donation database and complying with all the current regulations regarding human tissue collection for scientific research purposes.

Samples were obtained from individuals submitted to forensic autopsy exams during the first semester of 2012 at the North Branch (Porto) of the Portuguese National Institute of Legal Medicine (INML). Individuals from each of the following age groups were studied: 50-60 $(n=10), 60-70$ ( $n=10), 70-80(n=10), 80-90(n=9)$ and $\geq 90(n=3)$ years old. Inclusion criteria were a) the absence of a history of known neurodegenerative, neurological or psychiatric disorders, b) the absence of injuries involving the central nervous system (CNS), and c) macroscopically normal tissues.

Samples from two individuals with documented Alzheimer's disease (women, 73 and 85 years old) and one with Parkinson's disease (woman, 91 years old) were also collected. 


\section{Sample collection}

Samples were collected by the pathologists at the INML following a standard protocol.

To prevent sample contamination, all materials in contact with the samples, including the stainless steel tools used by the pathologists, were previously decontaminated with a $5 \%(\mathrm{v} / \mathrm{v})$ nitric acid solution prepared from concentrated $(\geq 69 \%) \mathrm{HNO}_{3}$ (Sigma-Aldrich, Germany) and thoroughly rinsed with ultrapure water (resistivity $18.2 \mathrm{M} \Omega . \mathrm{cm}$ at $25{ }^{\circ} \mathrm{C}$ ) produced by a Milli-Q water purification system (Millipore, USA).

After removing the brain from the cranium, the contaminating blood was washed away with ultrapure water. The meninges were removed with plastic tweezers, and the brain was washed again with ultrapure water to minimise sample contamination with blood or cerebrospinal fluid.

The brain areas studied were defined based on Paine and Lowe's recommendations for regions to be sampled when a neurodegenerative disease is suspected [26]. Using decontaminated plastic knives, tissue fragments (approximately $1 \mathrm{~cm}^{3}$ ) were collected from the following brain areas: the frontal cortex (1); superior (2A) and middle (2B) temporal gyri; basal ganglia, including the caudate nucleus (3A), putamen (3B) and globus pallidus (3C); cingulated gyrus (4); hippocampus (5); inferior parietal lobule (6); visual cortex of the occipital lobe (7); midbrain, including the substantia nigra at the level of the third nerve (8); pons (locus coeruleus) (9); medulla (10); and cerebellum (dentate nucleus) (11). Samples were stored in decontaminated polypropylene tubes (Sarstedt, Germany) at -4 ${ }^{\circ} \mathrm{C}$ until analysis. 


\section{Sample pre-treatment}

After defrosting, the brain samples were thoroughly washed with ultrapure water and placed in a dry oven (Raypa, Spain) at $110^{\circ} \mathrm{C}$ until constant weight (ca. 24 hours). Dried samples (ca. 100-500 mg)

were weighed directly in the microwave digestion vessels, which had been previously decontaminated with $10 \%(\mathrm{v} / \mathrm{v}) \mathrm{HNO}_{3}$ and thoroughly rinsed with ultrapure water. Samples were digested using $2.5 \mathrm{~mL}$ of concentrated $(\geq 65 \% \mathrm{~m} / \mathrm{m}) \mathrm{HNO}_{3}\left(\right.$ TraceSELECT ${ }^{\circledR}$, Fluka, France) and 1.0 $\mathrm{mL}$ of $\geq 30 \%(\mathrm{v} / \mathrm{v}) \mathrm{H}_{2} \mathrm{O}_{2}$ solution (TraceSELECT ${ }^{\circledR}$, Fluka, Germany). The sample digestion was performed in an MLS 1200 Mega microwave oven from Milestone (Italy) equipped with an HPR 1000/10 rotor using the following power (W)/time (min) program: 250/1, 0/2, 250/5, 400/5 and 600/5. After cooling, sample solutions were made up to $50 \mathrm{~mL}$ with ultrapure water and stored in closed propylene tubes at $4{ }^{\circ} \mathrm{C}$ until analysis.

\section{Iron determination}

Fe determination was performed using a PerkinElmer (Germany) model 4100 ZL atomic absorption spectrometer (longitudinal Zeeman background correction) equipped with a transversely heated graphite atomiser (THGA), end-capped graphite tubes with an integrated L'vov platform (PerkinElmer Part No. B3 000653) and an AS-70 autosampler. An Intensitron ${ }^{\mathrm{TM}}$ (PerkinElmer) hollow cathode lamp was used as a light source $(\lambda=248.3 \mathrm{~nm})$. Argon of $99.9999 \%$ purity (Gasin, Portugal) was used as an inert gas. A commercial magnesium nitrate solution (ref. 63043; Fluka, Switzerland) was used to prepare the matrix modifier solution [5 $\mu \mathrm{L}=15 \mu \mathrm{g} \operatorname{Mg}\left(\mathrm{NO}_{3}\right)_{2}$ ]. The instrumental conditions and graphite furnace program used are summarised in Table 1. 
Table 1

Instrument settings and graphite furnace program for Fe determination.

\begin{tabular}{|c|c|c|c|}
\hline \multicolumn{2}{|c|}{ Parameter } & \multicolumn{2}{|c|}{ Value } \\
\hline \multicolumn{2}{|c|}{$\begin{array}{l}\text { Wavelength } \\
\text { Slit width }\end{array}$} & \multicolumn{2}{|c|}{$248.3 \mathrm{~nm}$} \\
\hline \multicolumn{2}{|c|}{ Slit width } & \multicolumn{2}{|l|}{$0.2 \mathrm{~nm}$} \\
\hline \multicolumn{2}{|c|}{ Lamp current } & \multicolumn{2}{|l|}{$30 \mathrm{~mA}$} \\
\hline \multicolumn{2}{|c|}{ Inert gas } & \multicolumn{2}{|l|}{ Argon } \\
\hline \multicolumn{2}{|l|}{ Flow rate } & \\
\hline \multicolumn{2}{|c|}{ Background correction } & \multicolumn{2}{|c|}{$\begin{array}{l}250 \mathrm{~mL} / \mathrm{min}(0 \text { at the atomization step) } \\
\text { Longitudinal Zeeman-effect }\end{array}$} \\
\hline \multicolumn{2}{|c|}{ Sample injection volume } & \multicolumn{2}{|l|}{$15 \mu \mathrm{L}$} \\
\hline \multicolumn{2}{|c|}{ Matrix modifier injection volume } & \multicolumn{2}{|l|}{$4 \mu \mathrm{L}$} \\
\hline \multicolumn{2}{|c|}{ Measurement mode } & \multicolumn{2}{|c|}{ Integrated absorbance (A.s) } \\
\hline \multicolumn{2}{|c|}{ Integration time } & \multicolumn{2}{|l|}{$5 \mathrm{~s}$} \\
\hline \multicolumn{2}{|c|}{ Baseline Offset Correction (BOC) } & \multicolumn{2}{|l|}{$2 \mathrm{~s}$} \\
\hline \multicolumn{4}{|c|}{ Graphite furnace program } \\
\hline Step & Temp. $\left({ }^{\circ} \mathrm{C}\right)$ & Ramp (s) & Hold (s) \\
\hline Dry & 110 & 1 & 30 \\
\hline Dry & 130 & 15 & 30 \\
\hline Pyrolysis & 1400 & 10 & 20 \\
\hline Atomization & 2100 & 0 & 5 \\
\hline Cleaning & 2450 & 1 & 3 \\
\hline
\end{tabular}

Injection temperature: $20^{\circ} \mathrm{C}$.

The sample digests were diluted (100-fold) with $0.2 \%(\mathrm{v} / \mathrm{v}) \mathrm{HNO}_{3}$ solution before injection into the graphite tube. Sample solutions were measured in duplicate. For results with $\mathrm{RSD} \geq 10 \%$, an additional two injections were performed.

Calibration standards were also prepared by diluting a commercial multi-element standard solution (PerkinElmer Pure; Part No. N9300244) with $0.2 \%$ (v/v) $\mathrm{HNO}_{3}$ solution. Calibration curves were obtained with six calibration standards with concentrations ranging from 10 to $60 \mu \mathrm{g} / \mathrm{L}$.

\section{Analytical quality control}

Because human brain tissue is not available as a certified reference material (CRM) for Fe determination, DOLT-4 Dogfish Liver and DORM-3 Fish Protein CRMs for Trace Metals (National Research Council, Canada) were used for analytical quality control purposes. CRMs were subjected to the same sample pre-treatment and employed at the same concentration levels as the sample 
solutions. The values obtained were within the analytical uncertainty of the certified values (Table 2).

Table 2

Results $(\mu \mathrm{g} / \mathrm{g})$ obtained in the determination of Fe in DOLT-4 and DORM-3 Certified Reference Materials.

\begin{tabular}{cccc}
\hline \multicolumn{2}{c|}{ DOLT-4 } & \multicolumn{2}{c}{ DORM-3 } \\
\hline Reference value $^{*}$ & Experimental value & Reference value $^{*}$ & Experimental value $^{2}$ \\
$1833 \pm 75$ & $1934 \pm 63$ & $347 \pm 20$ & $349 \pm 30$ \\
\hline
\end{tabular}

*Results obtained using ICP-MS and ICP-AES.

For contamination control of the microwave-assisted acid digestion procedure, a sample blank was included in each digestion run (10 samples). In total, 77 sample blanks were run, and the mean Fe content obtained $(0.37 \mu \mathrm{g} / \mathrm{L})$ was subtracted from the sample values.

\section{Statistical evaluation}

The descriptive statistical parameters (mean and standard deviation) were calculated using Microsoft Office Excel 2010 (Microsoft Co., USA). The means were compared by an unpaired Student's t-test at a 0.05 significance level using GraphPad Prism 5 (GraphPad Software Inc., USA).

\section{Results and discussion}

\section{Regional distribution of Fe}

The results $(\mu \mathrm{g} / \mathrm{g}$, dry weight) for Fe determination in each of the 14 different brain regions studied are summarised in Table 3. 


\section{Table 3}

Fe levels (mean $\pm \mathrm{sd}, \mu \mathrm{g} / \mathrm{g}$ ) in 14 different regions of human brain (see footnote) of non-diseased individuals (n $=42 ; 71 \pm 12$ years old) according to age group.

\begin{tabular}{|c|c|c|c|c|c|c|}
\hline \multirow{3}{*}{$\begin{array}{c}\text { Brain } \\
\text { regions* }\end{array}$} & \multirow{3}{*}{ All individuals } & \multicolumn{5}{|c|}{ Age groups } \\
\hline & & [50-59] & [60-69] & [70-79] & [80-89] & $\geq 90$ \\
\hline & & $(n=10)$ & $(n=10)$ & $(n=10)$ & $(n=9)$ & $(n=3)$ \\
\hline 1 & $275 \pm 65$ & $241 \pm 41$ & $280 \pm 43$ & $315 \pm 72$ & $244 \pm 51$ & $306 \pm 135$ \\
\hline $2 \mathrm{~A}$ & $289 \pm 67$ & $269 \pm 55$ & $289 \pm 48$ & $312 \pm 70$ & $281 \pm 91$ & $306 \pm 86$ \\
\hline $2 \mathrm{~B}$ & $287 \pm 65$ & $269 \pm 55$ & $276 \pm 57$ & $308 \pm 77$ & $256 \pm 36$ & $382 \pm 81$ \\
\hline $3 \mathrm{~A}$ & $599 \pm 271$ & $533 \pm 268$ & $532 \pm 249$ & $607 \pm 259$ & $743 \pm 360$ & $398 \pm 215$ \\
\hline $3 B$ & $855 \pm 295$ & $777 \pm 267$ & $762 \pm 133$ & $848 \pm 351$ & $1155 \pm 363$ & $976 \pm 286$ \\
\hline $3 \mathrm{C}$ & $739 \pm 390$ & $577 \pm 266$ & $759 \pm 371$ & $593 \pm 269$ & $1062 \pm 526$ & $735 \pm 331$ \\
\hline 4 & $226 \pm 64$ & $194 \pm 73$ & $231 \pm 53$ & $246 \pm 57$ & $226 \pm 79$ & $243 \pm 43$ \\
\hline 5 & $239 \pm 54$ & $239 \pm 55$ & $239 \pm 66$ & $237 \pm 52$ & $246 \pm 64$ & $227 \pm 1$ \\
\hline 6 & $288 \pm 68$ & $279 \pm 67$ & $283 \pm 77$ & $305 \pm 62$ & $288 \pm 87$ & $272 \pm 21$ \\
\hline 7 & $332 \pm 113$ & $312 \pm 82$ & $308 \pm 79$ & $396 \pm 170$ & $307 \pm 107$ & $347 \pm 69$ \\
\hline 8 & $293 \pm 106$ & $257 \pm 89$ & $321 \pm 119$ & $277 \pm 101$ & $327 \pm 118$ & $271 \pm 133$ \\
\hline 9 & $98 \pm 43$ & $87 \pm 30$ & $98 \pm 40$ & $99 \pm 40$ & $116 \pm 70$ & $85 \pm 45$ \\
\hline 10 & $56 \pm 25$ & $48 \pm 19$ & $56 \pm 26$ & $71 \pm 21$ & $45 \pm 10$ & $48 \pm 43$ \\
\hline 11 & $283 \pm 114$ & $244 \pm 135$ & $287 \pm 129$ & $299 \pm 98$ & $305 \pm 103$ & $288 \pm 139$ \\
\hline $\begin{array}{c}\text { Mean of } \\
\text { studied } \\
\text { regions }\end{array}$ & $347 \pm 63$ & $309 \pm 56$ & $335 \pm 52$ & $346 \pm 47$ & $402 \pm 7$ & $358 \pm 22$ \\
\hline
\end{tabular}

*1-Frontal cortex; 2A-Superior temporal gyrus; 2B-Middle temporal gyrus; 3A-Caudate nucleus, 3BPutamen; 3C-Globus pallidus; 4-Cingulated gyrus; 5-Hippocampus; 6-Inferior parietal lobule; 7-Visual cortex of the occipital lobe; 8-Midbrain, 9-Pons 10-Medulla; 11-Cerebellum.

The results showed that the $\mathrm{Fe}$ distribution in an adult human brain is quite heterogeneous. Regardless of age group, the highest levels were found in the basal ganglia (putamen: 328-1628 $\mu \mathrm{g} / \mathrm{g}$, globus pallidus: $225-1870 \mu \mathrm{g} / \mathrm{g}$, caudate nucleus: $199-1477 \mu \mathrm{g} / \mathrm{g}$ ) and the lowest in the pons $(11-253 \mu \mathrm{g} / \mathrm{g})$ and medulla $(13-115 \mu \mathrm{g} / \mathrm{g})$. Previously published data $[3,25]$ also suggested that normal $\mathrm{Fe}$ content within the brain varies significantly by region, with the highest levels being found in the substantia nigra, basal ganglia, hippocampus and subcortical brain regions. House et al. [23] evaluated the Fe content in the frontal, temporal, parietal and occipital lobes of 60 elderly individuals (70-103 years old) and found an overall tissue content of $c a .290 \mu \mathrm{g} / \mathrm{g}$ (range: 112-8350 $\mu \mathrm{g} / \mathrm{g}$ ) with 
significant differences $(\mathrm{p}<0.05)$ between the frontal and occipital as well as the frontal and parietal lobes. In our study, no difference was found between the latter two regions.

The basal ganglia are the largest component of the extrapyramidal system and are considered part of the motor system [27]. However, the cerebellum, another brain region involved in motor coordination [27], presented much lower Fe levels $(109-520 \mu \mathrm{g} / \mathrm{g})$. The reason for this selective distribution of $\mathrm{Fe}$ in distinct areas related to motor functions is unknown. Increased oxygen demand cannot provide a full explanation because other brain regions with intense metabolic activity do not show comparable Fe levels [28].

\section{Age-related changes}

Globally, i.e., considering the mean value of the results obtained for the 14 regions, a tendency for an age-related increase in Fe levels in brain was found (Fig. 1a).

This tendency was particularly significant in some specific areas. The most significant direct correlation between Fe levels and age was found in the caudate nucleus, putamen and globus pallidus (Fig. 1b-d). 


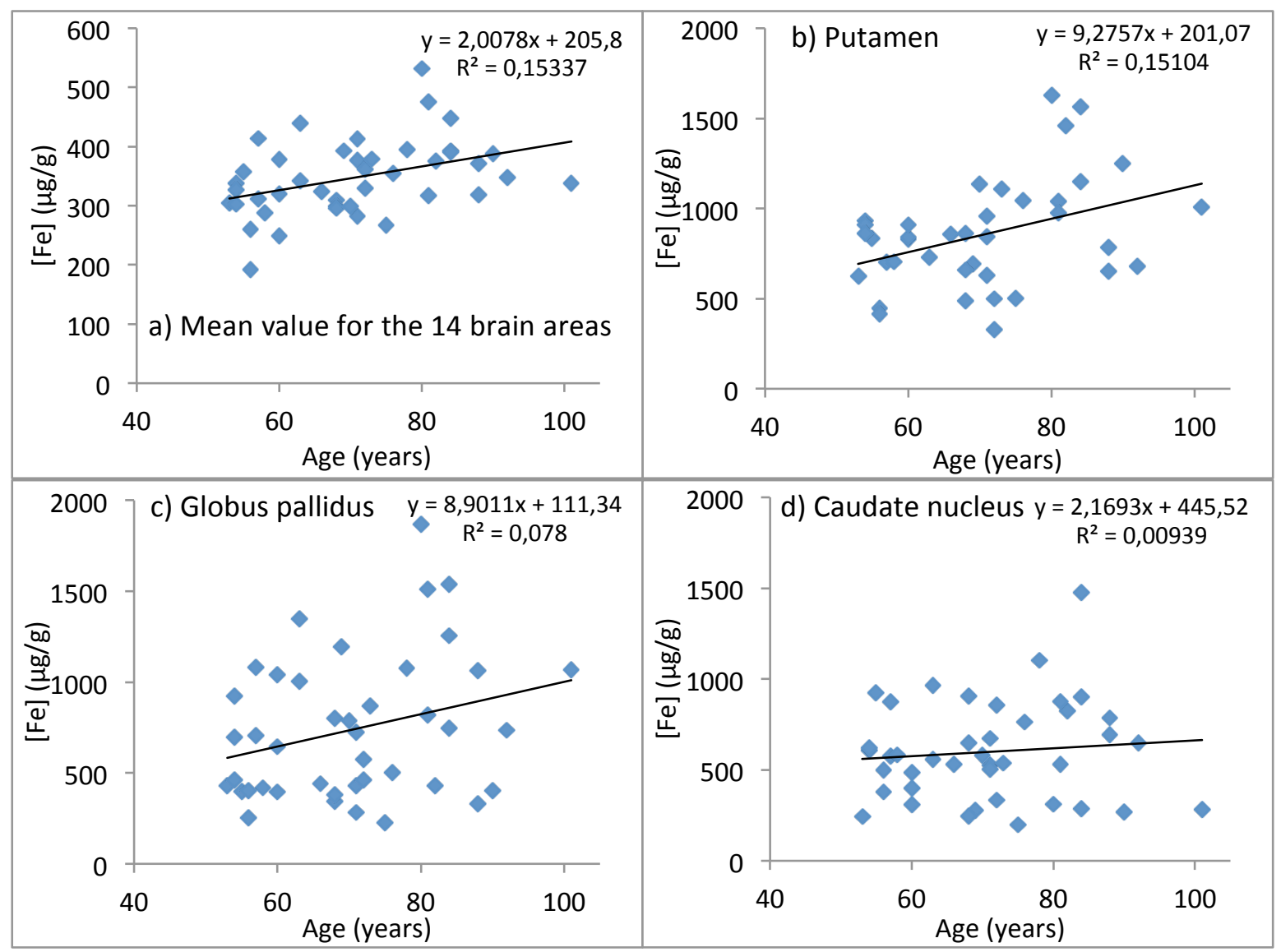

Fig. 1. Relationship between Fe brain levels ( $\mu \mathrm{g} / \mathrm{g}$, dry weight) and age (years): mean value of the different 14 brain regions for each individual $(\mathrm{n}=42)$ (a) and Fe levels in putamen $(\mathrm{b})$, globus pallidus (c) and caudate nucleus (d).

Several other post-mortem and in vivo studies also found an increase in Fe levels with age in the subcortical and some cortical grey matter regions in healthy individuals. Xu et al. [29] reported an age-related $\mathrm{Fe}$ accumulation in the putamen from 22 years to over 70 years, reaching maximal values in approximately the sixth decade. The authors reported that the Fe levels in the globus pallidus and caudate nucleus remained unchanged with age, but our results show a positive correlation in these regions. Aquino et al. [30] also report an exponential increase in Fe with increasing age in all the basal ganglia of neurologically healthy individuals ( $n=80,1-80$ years old). Adisetiyo et al. [31] found 
significantly lower Fe levels in adolescents $(\mathrm{n}=16,13-18$ years old) than adults $(\mathrm{n}=10,21-44$ years old) in the caudate nucleus, putamen and globus pallidus.

Hebbrecht et al. [22] studied five regions (the basal ganglia, cerebral cortex, cerebral white matter, brainstem and cerebellar cortex) of the human brain ( $\mathrm{n}=18,7-79$ years old) and found a strong correlation between Fe levels and age in all these areas. Bilgic et al. [32] also found that elderly people had significantly higher Fe levels in the striatal regions of the putamen, caudate nucleus, globus pallidus and substantia nigra than younger people. Zecca et al. [33] evaluated Fe content in the substantia nigra during ageing and found a smooth increase within the considered age interval (16-90 years old).

In a recent study by Exley et al. [34], no statistically significant correlation between brain Fe levels and age was found for a group of 60 elderly individuals (70-103 years old), which may indicate that this trend disappears in very old people.

When individuals were grouped by gender, quite similar Fe levels were observed ( $346 \pm 36 \mu \mathrm{g} / \mathrm{g}$ for women versus $348 \pm 73 \mu \mathrm{g} / \mathrm{g}$ for men; $\mathrm{p}=0.976$ ), with a lower inter-individual variability in women. $\mathrm{Xu}$ et al. [28] also reported no significant gender-related differences in brain Fe levels. This is an interesting finding because it is well known that women have lower whole-body Fe levels than men; therefore, a lower brain level could also be expected. The female subgroup $(n=15)$ had a higher mean age $(77 \pm 12$ years old) than the male subgroup ( $\mathrm{n}=27 ; 67 \pm 11$ years old), but this is not a sufficient explanation for the similarity in brain Fe levels because our results also showed that the positive correlation between Fe levels and age is not observed in women (Fig. 2). 


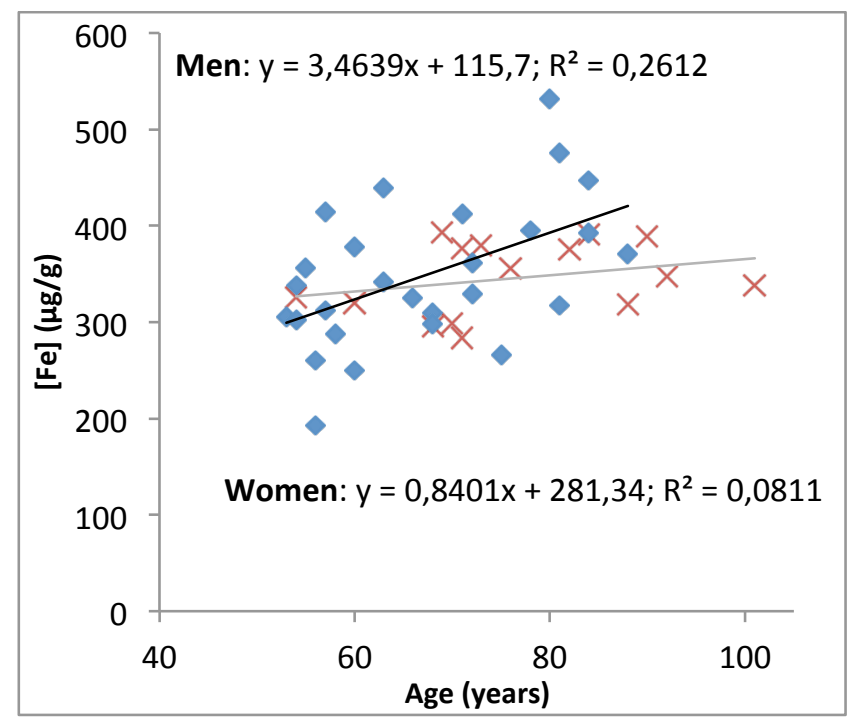

Fig. 2. Relationship between brain Fe levels $(\mu \mathrm{g} / \mathrm{g})$ and age (years) in men $(\diamond)$ and women $(\times)$.

\section{Disease-related changes}

Abnormally high brain levels of Fe have been reported in several NDs, including Parkinson's disease and Alzheimer's disease [35-39]. Because brain tissue is rich in oxygen and fatty acids, elevated Fe levels provides a perfect environment for oxidative stress and severe tissue damage [37].

When compared with non-diseased subjects of the same age group, the brain Fe levels of the two Alzheimer's disease patients were elevated in the caudate nucleus (by factors of 1.9 and 1.7) and the hippocampus (by factors of 1.3 and 2.1), the main brain region associated with memory and spatial navigation [40]. The Parkinson's disease patient presented more pronounced differences in the basal ganglia (the brain regions with the highest Fe levels in non-diseased individuals): the Fe levels were elevated in the caudate nucleus (by a factor of 2.3) and the globus pallidus (by a factor of 2.4), which are both associated with motor functions [26]. 


\section{Conclusion}

This study, which directly determined Fe levels in 14 different brain regions in 42 non-diseased individuals, provides further evidence of the quite heterogeneous distribution of $\mathrm{Fe}$ in the human brain.

Globally (i.e., considering the mean value of the results obtained for the 14 regions in each individual), a significant age-related tendency for increased brain Fe levels was found. The basal ganglia were the brain regions where this direct correlation was most significant, whereas the correlation was almost absent in several other brain regions.

No significant gender-related difference was observed in brain Fe levels. However, the direct correlation between total Fe levels and age was not observed in women; their brain Fe levels showed remarkable consistency in the age interval studied.

This work provides a comprehensive and updated background for Fe levels in non-diseased human brains. It may be a significant contribution for defining "normal" Fe levels, which would allow future interpretations of results obtained in studies of patients affected by ND. This work also highlights the need for clearly defining the brain areas that are effectively studied and the age of the patients when performing such studies.

\section{Acknowledgements}

The authors thank the Universidade do Porto and Santander Totta for financial support through the project "TRAIN: Trace elements in human brain: age-related changes and anatomic region specific differences" (PP_IJUP 2011 342). 


\section{References}

[1] National Institute on Aging (US National Institutes of Health) and WHO: Global Health and Aging Report. NIH Publication no 11-7737, October 2011 [cited 2012, 7 March 2012]. Available from: http://www.nia.nih.gov.

[2] Castellani RJ, Rolston RK, Smith MA. Alzheimer disease. Dis Mon. 2010;56(9):484-546.

[3] Rivera-Mancia S, Perez-Neri I, Rios C, Tristan-Lopez L, Rivera-Espinosa L, Montes S. The transition metals copper and iron in neurodegenerative diseases. Chem Biol Interact. 2010;186(2):184-99.

[4] Jomova K, Vondrakova D, Lawson M, Valko M. Metals, oxidative stress and neurodegenerative disorders. Mol Cell Biochem. 2010;345(1-2):91-104.

[5] Fraga CG. Relevance, essentiality and toxicity of trace elements in human health. Mol Aspects Med. 2005;26(4-5):235-44.

[6] Zheng W, Monnot AD. Regulation of brain iron and copper homeostasis by brain barrier systems: implication in neurodegenerative diseases. Pharmacol Ther. 2012;133(2):177-88.

[7] Lhermitte J, Kraus WM, McAlpine D. On the occurrence of abnormal deposits of iron in the brain in Parkinsonism with special reference to its localisation. J Neurol Psychiatry. 1924;5(19):195-208.

[8] Sayre LM, Perry G, Harris PL, Liu Y, Schubert KA, Smith MA. In situ oxidative catalysis by neurofibrillary tangles and senile plaques in Alzheimer's disease: a central role for bound transition metals. $\mathrm{J}$ Neurochem. 2000;74(1):270-9.

[9] Bush AI. Metals and neuroscience. Curr Opin Chem Biol. 2000;4(2):184-91.

[10] Gotz ME, Double K, Gerlach M, Youdim MB, Riederer P. The relevance of iron in the pathogenesis of Parkinson's disease. Ann N Y Acad Sci. 2004;1012:193-208.

[11] Michaeli S, Oz G, Sorce DJ, Garwood M, Ugurbil K, Majestic S, et al. Assessment of brain iron and neuronal integrity in patients with Parkinson's disease using novel MRI contrasts. Mov Disord. 2007;22(3):334-40.

[12] Crichton RR, Dexter DT, Ward RJ. Brain iron metabolism and its perturbation in neurological diseases. J Neural Transm. 2011;118(3):301-14.

[13] Paul MC, Parsons CH, Calford MB, von Nagy-Felsobuki EI. Multi-elemental analysis of brain tissue from healthy Wistar rats using sector field inductively coupled plasma mass spectrometry. Spectrochim Acta, Part B. 2004;59(9):1485-90.

[14] Saito T, Itoh T, Fujimura M, Saito K. Age-dependent and region-specific differences in the distribution of trace elements in 7 brain regions of Long-Evans Cinnamon (LEC) rats with hereditary abnormal copper metabolism. Brain Res. 1995;695(2):240-4.

[15] Hozumi I, Hasegawa T, Honda A, Ozawa K, Hayashi Y, Hashimoto K, et al. Patterns of levels of biological metals in CSF differ among neurodegenerative diseases. J Neurol Sci. 2011;303(1-2):95-9.

[16] Alimonti A, Bocca B, Pino A, Ruggieri F, Forte G, Sancesario G. Elemental profile of cerebrospinal fluid in patients with Parkinson's disease. J Trace Elem Med Biol. 2007;21(4):234-41.

[17] Forte G, Bocca B, Senofonte O, Petrucci F, Brusa L, Stanzione P, et al. Trace and major elements in whole blood, serum, cerebrospinal fluid and urine of patients with Parkinson's disease. J Neural Transm. 2004;111(8):1031-40.

[18] Michalke B, Nischwitz V. Review on metal speciation analysis in cerebrospinal fluid-current methods and results: a review. Anal Chim Acta. 2010;682(1-2):23-36.

[19] Gellein K, Skogholt JH, Aaseth J, Thoresen GB, Lierhagen S, Steinnes E, et al. Trace elements in cerebrospinal fluid and blood from patients with a rare progressive central and peripheral demyelinating disease. J Neurol Sci. 2008;266(1-2):70-8.

[20] Andrasi E, Orosz L, Bezur L, Ernyei L, Molnar Z. Normal Human Brain Analysis. Microchem J. 1995;51(1-2):99-105. 
[21] Deibel MA, Ehmann WD, Markesbery WR. Copper, iron, and zinc imbalances in severely degenerated brain regions in Alzheimer's disease: possible relation to oxidative stress. J Neurol Sci. 1996;143(1-2):137-42.

[22] Hebbrecht G, Maenhaut W, Reuck JD. Brain trace elements and aging. Nucl Instrum Methods Phys Res, Sect B. 1999;150(1-4):208-13.

[23] House E, Esiri M, Forster G, Ince PG, Exley C. Aluminium, iron and copper in human brain tissues donated to the Medical Research Council's Cognitive Function and Ageing Study. Metallomics. 2012;4(1):5665 .

[24] Rajan MT, Jagannatha Rao KS, Mamatha BM, Rao RV, Shanmugavelu P, Menon RB, et al. Quantification of trace elements in normal human brain by inductively coupled plasma atomic emission spectrometry. J Neurol Sci. 1997;146(2):153-66.

[25] Andrási E, Igaz S, Szoboszlai N, Farkas É, Ajtony Z. Several methods to determine heavy metals in the human brain. Spectrochim Acta, Part B. 1999;54(5):819-25.

[26] Paine SML, Lowe JS. Approach to the post-mortem investigation of neurodegenerative diseases: from diagnosis to research. Diagn Histopathol. 2011;17(5):211-6.

[27] Swenson R. Review of Clinical and Functional Neuroscience 2006 [7 March 2012]. Available from: https://www.dartmouth.edu/ rswenson/NeuroSci/index.html.

[28] Andrasi E, Farkas E, Gawlik D, Rosick U, Bratter P. Brain Iron and Zinc Contents of German Patients with Alzheimer Disease. J Alzheimers Dis. 2000;2(1):17-26.

[29] Xu X, Wang Q, Zhang M. Age, gender, and hemispheric differences in iron deposition in the human brain: an in vivo MRI study. Neuroimage. 2008;40(1):35-42.

[30] Aquino D, Bizzi A, Grisoli M, Garavaglia B, Bruzzone MG, Nardocci N, et al. Age-related iron deposition in the basal ganglia: quantitative analysis in healthy subjects. Radiology. 2009;252(1):165-72.

[31] Adisetiyo V, Jensen JH, Ramani A, Tabesh A, Di Martino A, Fieremans E, et al. In vivo assessment of age-related brain iron differences by magnetic field correlation imaging. J Magn Reson Imaging. 2012;36(2):322-31.

[32] Bilgic B, Pfefferbaum A, Rohlfing T, Sullivan EV, Adalsteinsson E. MRI estimates of brain iron concentration in normal aging using quantitative susceptibility mapping. Neuroimage. 2012;59(3):2625-35.

[33] Zecca L, Zucca FA, Toscani M, Adorni F, Giaveri G, Rizzio E, et al. Iron, copper and their proteins in substantia nigra of human brain during aging. Journal of Radioanalytical and Nuclear Chemistry. 2005;263(3):733-7.

[34] Exley C, House E, Polwart A, Esiri MM. Brain burdens of aluminum, iron, and copper and their relationships with amyloid-beta pathology in 60 human brains. J Alzheimers Dis. 2012;31(4):725-30.

[35] Quintana C, Bellefqih S, Laval JY, Guerquin-Kern JL, Wu TD, Avila J, et al. Study of the localization of iron, ferritin, and hemosiderin in Alzheimer's disease hippocampus by analytical microscopy at the subcellular level. J Struct Biol. 2006;153(1):42-54.

[36] Ong WY, Farooqui AA. Iron, neuroinflammation, and Alzheimer's disease. J Alzheimers Dis. 2005;8(2):183-200; discussion 9-15.

[37] Sadrzadeh SM, Saffari Y. Iron and brain disorders. Am J Clin Pathol. 2004;121 Suppl:S64-70.

[38] Berg D, Becker G, Riederer P, Riess O. Iron in neurodegenerative disorders. Neurotox Res. 2002;4(78):637-53.

[39] Fasano M, Bergamasco B, Lopiano L. Modifications of the iron-neuromelanin system in Parkinson's disease. J Neurochem. 2006;96(4):909-16.

[40] Good M. Spatial Memory and Hippocampal Function: Where are we now? Psicológica. 2002;23:109-38.

[41] Andrasi E, Farkas E, Scheibler H, Reffy A, Bezur L. Al, Zn, Cu, Mn and Fe levels in brain in Alzheimer's disease. Arch Gerontol Geriatr. 1995;21(1):89-97.

[42] von Bohlen und Halbach O, Dermietzel R. Neurotransmitters (chapter 3). Neurotransmitters and Neuromodulators: Wiley-VCH Verlag GmbH \& Co. KGaA; 2003. 
[43] Griffiths PD, Crossman AR. Distribution of iron in the basal ganglia and neocortex in postmortem tissue in Parkinson's disease and Alzheimer's disease. Dementia. 1993;4(2):61-5.

[44] Griffiths PD, Dobson BR, Jones GR, Clarke DT. Iron in the basal ganglia in Parkinson's disease. An in vitro study using extended X-ray absorption fine structure and cryo-electron microscopy. Brain. 1999;122 ( Pt 4):667-73.

[45] Sofic E, Riederer P, Heinsen H, Beckmann H, Reynolds GP, Hebenstreit G, et al. Increased iron (III) and total iron content in post mortem substantia nigra of parkinsonian brain. J Neural Transm. 1988;74(3):199205.

[46] Dexter DT, Wells FR, Lees AJ, Agid F, Agid Y, Jenner P, et al. Increased nigral iron content and alterations in other metal ions occurring in brain in Parkinson's disease. J Neurochem. 1989;52(6):1830-6. 